\title{
Large scale artificial rearing of Anastrepha sp.1 aff. fraterculus (Diptera: Tephritidae) in Brazil
}

\author{
Julio Marcos Melges Walder ${ }^{*}$, Renata Morelli ${ }^{1,3}$, Karen Zamboni Costa ${ }^{1}$, Kenya Martins Faggioni ${ }^{1}$, Patrícia Alessandra Sanches ${ }^{1}$, \\ Beatriz Aguiar Jordão Paranhos², José Maurício Simões Bento ${ }^{3}$, Maria de Lourdes Zamboni Costa ${ }^{1}$
}

'University of São Paulo/CENA - Lab. of Radioentomology, Av. Centenário, 303, C.P. 96 - 13400-970 - Piracicaba, SP - Brazil.

2Embrapa Tropical Semiarid, Rod. BR 428, km 152, C.P. 23

- 56302-970 - Petrolina, PE - Brazil.

3University of São Paulo/ESALQ - Dept. of Entomology and Acarology, Av. Pádua Dias, 11, C.P. 09 - 13418-900 -

Piracicaba, SP - Brazil.

*Corresponding author <jmwalder@cena.usp.br>

Edited by: Richard V. Glatz

Received July 29, 2013

Accepted February 18, 2014
ABSTRACT: Some species of the genus Anastrepha (Diptera: Tephritidae) are successfully managed by matching the sterile insect technique with parasitoid releases. Such strategies used in integrated pest management can be implemented only where insect mass-rearing programs are feasible. In this study, we show the process of domestication, rearing technology and quality control data obtained from 54 generations of Anastrepha sp.1 aff. fraterculus (Wiedemann, 1830) kept under fully artificial conditions. Eggs were collected by an artificial oviposition panel consisting of one side of the cage made of blue voile fabric externally covered with a thin layer of silicon rubber. They were then air-bubbled in water at $25^{\circ} \mathrm{C}$ for $48 \mathrm{~h}$ before seeding. Larvae were reared on the regular laboratory artificial diet with $66 \%$ of agar reduction turning over a semi-liquid diet, which reduced costs and improved insect quality. The adult and larval diets were composed of local ingredients including hydrolyzed yeast. When large-scale production of this fly is contemplated, the critical stage is larval development. This system of artificial rearing for A. fraterculus sp. 1 developed in Brazil, allows for the production of a large number of insects of excellent quality using local ingredients and less agar in diet composition than the original medium used for this species. By reducing the interval of egg collection, the system might be optimized in terms of insect yield and, therefore, meet the demands of $A$. fraterculus sp.1 with regard to integrated pest management purposes.

Keywords: insect production, insect domestication, sterile insect technique, integrated pest management, fruit fly

\section{Introduction}

Integrated Pest Management (IPM) programs targeted at fruit pests encourage biological control techniques, reduction of chemical insecticide use and increases in natural enemy populations. Besides biological control, the Sterile Insect Technique (SIT) is another strategy that meets the food safety and quarantine requirements of the international fruit trade. It entails routine releases of sterile insects over a wide area where they will mate with females in the wild and consequently give rise to a gradual decrease in the pest population (Knipling, 1955). Fruit flies count amongst the major pests in agriculture worldwide because they directly affect yield by causing damage to fruit. Furthermore, quarantine restrictions are placed on the international trading of fruit from areas where fruit flies are present, which can have serious negative impacts on a country's economy. Two strategies used worldwide in IPM fruit fly programs are Augmentative Biological Control (ABC) with parasitoids and SIT, which are complementary and work together quite efficiently (Knipling, 1992). To improve SIT, mass rearing of both target fly and parasitoids are required. For insect mass-rearing, procedures are needed to foster high production of high quantity offspring at the lowest cost. In the genus Anastrepha, $A$. obliqua and $A$. ludens in Mexico (Montoya et al., 2000), $A$. ludens in the USA (USDA, 2010) and $A$. suspensa in the USA (Sivinski et al., 1996) have been successfully man- aged with SIT or ABC. Some studies testing those strategies for $A$. fraterculus control have also been conducted in Argentina (Allinghi et al., 2007; Gomez-Cendra et al., 2007; Ovruski et al., 2011; Rull et al., 2012; Segura et al., 2009; Vera et al., 2007).

In Brazil, $A$. fraterculus is the most important species among Anastrepha spp. in several fruit crops (Malavasi et al., 2000). This study aimed at developing a method of large-scale rearing for $A$. fraterculus with the lowest cost, which is a major step for implementing of integrated management programs using $\mathrm{ABC}$ and SIT. The study also presents production and quality control data spanning 54 generations of mass-rearing.

\section{Materials and Methods}

\section{Domestication of $A$. fraterculus sp. 1}

Parental flies were collected from infested indigenous fruits (Eugenia pyriformis Cambess.), from Piracicaba $\left(22^{\circ} 42^{\prime} \mathrm{S} ; 47^{\circ} 47^{\prime} \mathrm{W} ; 503 \mathrm{~m}\right)$, in the state of São Paulo, Brazil, and were kept in mesh-covered containers on vermiculite until all larvae had hopped off of the fruit and entered the pupal stage. Pupae were sieved from vermiculite, put into a small screened cage for emergence, and kept in a climate-controlled room $\left(26 \pm 2{ }^{\circ} \mathrm{C}\right)$; relative humidity (RH) of $70-80 \%$, and $14 \mathrm{~h}$ of photophase at approximately 12,000 lux.

Adults (262 females and 250 males) were transferred to screened cages $(30 \times 30 \times 30 \mathrm{~cm})$ where they 
were given water (moist cotton), food (hydrolyzed yeast Saccharomyces cerevisiae and caster sugar at $\mathrm{v}: \mathrm{v}$ ratio of $1: 3$ respectively), and one papaya fruit (Carica papaya) weighing about $350 \mathrm{~g}$ for natural oviposition. To assure there had been no previous fruit flies infestation fresh mature green papaya fruits were obtained from the local market (Seo and Tang, 1982).

To start the colony off, the first generation was reared only on fruit, from which 100 pupae were obtained ( $81 \%$ adult eclosion; 42 females, 39 males). For the second generation, besides papaya for oviposition, the cage had also one side made of blue voile fabric that was externally covered with a thin layer of silicon rubber (<0.5-mm thick), which served as an oviposition panel. Papaya fruits were replaced every other day and set onto a thin layer of vermiculite on plastic trays where they remained for 13 days to facilitate larval development. Third instar larvae were removed from the rotten papayas and kept for eight days in vermiculite for pupation.

Pupae were sieved and put in a new cage to begin the next generation of the colony. The small number of eggs that were laid on the oviposition panel were carefully removed from the outer surface with a soft brush and placed on wet filter paper inside Petri dishes and kept at $25 \pm 1{ }^{\circ} \mathrm{C}$ for $72 \mathrm{~h}$. The newly-hatched larvae were transferred with a soft brush to the regular artificial diet (50 larvae per $10 \mathrm{~mL}$ of diet) where they remained for the whole larval development period (Salles, 1992). Adults originating from these eggs were maintained in cages without papaya to artificially select for females to oviposit through the oviposition panel.

By using papaya as an oviposition and a larval substrate, the first generations reared in the laboratory were guaranteed and no additional collections of infested fruit in the field were needed as in the case of high insect mortality or poor oviposition under artificial conditions. Thus, throughout the domestication period of five generations, two colonies of $A$. fraterculus sp. 1 were kept; one was reared directly on papaya fruit, and the other included artificial oviposition and larval substrates.

\section{Artificial rearing of $A$. fraterculus sp. 1}

From the sixth generation onwards, $A$. fraterculus sp. 1 rearing was conducted using artificial conditions exclusively. Several specimens of adults, larvae and eggs were identified. Morphology of the aculeus and eggs as well as larva chromosomal analysis confirmed it to be a pure colony of Anastrepha sp.1 aff. fraterculus (Araújo and Zucchi, 2006; Selivon et al., 2005).

Adults were kept in cages $(30 \times 50 \times 100 \mathrm{~cm})$ with bottom and corners made of aluminum, and front and back of acrylic; top and one side of screen for ventilation, and the remaining side $(50 \times 100 \mathrm{~cm})$ an oviposition panel made of blue voile fabric that was externally covered with a thin layer of silicon rubber $1<0.5-\mathrm{mm}$ thick). At the top of the cage, there was a food station shaped in the form of a half-cut pipe (diameter of $10 \mathrm{~cm}$ ). In generations 6-16 adults were fed the same diet as de- scribed earlier for domestication. From the $17^{\text {th }}$ generation onwards, raw wheat germ was added into the diet to improve egg hatch (Vera, M.T. personal communication) at the v:v ratio of one part of raw wheat germ : one part hydrolyzed yeast : three parts sugar.

In the $26^{\text {th }}$ generation the imported yeast was replaced by a local one, Bionis YE MF$^{\circledR}$ (Morelli et al., 2012; Silva Neto et al., 2012). Below the food station there was also a water supply (deionized water and sodium benzoate solution at $0.03 \%$ to avoid fungal growth), which was closed but had a single longitudinal gap at the top through which a filter paper allowed access to water. Each cage held $70 \mathrm{~mL}$ of pupae, which corresponded to approximately 1,960 adults. Adults were held under controlled conditions $\left(26 \pm 2{ }^{\circ} \mathrm{C} ; 70-80 \% \mathrm{RH}, 14 \mathrm{~h}\right.$ of photophase at about 12,000 lux).

A moistened spongecloth was attached to a transparent PVC cover and placed outside in parallel position to the oviposition panel to prevent egg desiccation. Ovipositing females were attracted to the panel by fluorescent lamps placed behind it. They introduced the ovipositor through the fabric mesh leaving the eggs trapped on the outer surface of the voile fabric. Eggs were removed by applying a gentle spray of water onto the panel and gathering them with a tray placed under the cage every $24 \mathrm{~h}$ for 15-20 days (Vera et al., 2007) and, thereafter, the adults were discarded.

The eggs were washed with filtered water solution of sodium benzoate at $0.03 \%$ for five minutes to reduce microbial contamination of the artificial diet. After measuring the volume of eggs collected ( $1 \mathrm{~mL}$ contains 11,700 eggs), they were transferred to an Erlenmeyer flask (500 $\mathrm{mL})$ for air bubbling in filtered water (v:v ratio of $1 \mathrm{~mL}$ of eggs: $20 \mathrm{~mL}$ of water) at $25^{\circ} \mathrm{C}$ for $48 \mathrm{~h}$ before seeding.

Up to the $10^{\text {th }}$ generation, larvae were reared on the diet promulgated by Salles (1992) as follows: sugar $(6.0 \%)$, wheat germ $(6.0 \%)$, brewer's yeast $(6.0 \%)$, sodium benzoate $(0.1 \%)$, methylparaben $(0.8 \%)$, hydrochloric acid $(0.6 \%)$, agar $(1.0 \%)$ and water (q.s.). From this generation onwards, the diet was modified by reducing the agar concentration. The $11^{\text {th }}$ generation was selected for defining the appropriate agar concentration for massrearing diets with lower concentrations of agar 10.30 , $0.32,0.34,0.36,0.40$ and $0.70 \%$ ) which were then compared with that of Salles (1992) with regard to quality parameters to be applied to the flies. Each treatment was replicated ten times. The eggs were bubbled in water as described above, and samples of $0.1 \mathrm{~mL}$ were seeded on $200 \mathrm{~mL}$ of diet placed in plastic pots $(500 \mathrm{~mL})$.

The pots were covered with perforated lids and kept in a climate-controlled room $\left(24 \pm 2{ }^{\circ} \mathrm{C}, 70 \% \mathrm{RH}\right)$ for 10-12 days until larvae reached late third instar. Larvae were collected by dissolving and washing the diet under water on a sieve. They were then placed on thin and moist vermiculite (v:v ratio of $1: 2)$ in plastic trays for pupation. These trays were kept in dark rooms $(24 \pm 2$ $\left.{ }^{\circ} \mathrm{C}, 65-75 \% \mathrm{RH}\right)$ for eight days. Pupae were then softly sieved and counted. To estimate the quality parameters, 
two samples of 100 pupae (eight days old) were taken from each replicate: one sample was used to assess pupal weight and flight ability according to standard protocols (FAO, 2003), and the other sample was used to determine emergence rate and sex ratio.

Egg-adult period was considered to be the number of days between egg collection and the date of emergence; emergence rate was estimated as (number of emerged flies) $100^{-1}$; the sex ratio as (number of females) (number of females + males) $^{-1}$; flight ability as (number of flying adults) (number of adults emerged) $)^{-1}$ and the egg-pupae recovery as (number of eggs seeded) (number of pupae recovered $)^{-1}$. Larval viability was assessed by inoculating 200 newly hatched larvae in each diet pot. Late third instar larvae were separated from the diets and placed on vermiculite for pupation as described above. Recovered pupae were counted and larval viability was estimated as (the number of larvae inoculated) (number of pupae recovered) $)^{-1}$.

With regard to the rearing procedures, one to three kilograms of larval diet $(0.34 \%$ of agar) were placed in plastic trays $(35 \times 25 \times 7 \mathrm{~cm})$ and the bubbled eggs were seeded on larval diet at 1:100 volume ratio of eggs: diet. The trays were covered with crimp fabric and kept in a climate-controlled room $\left(24 \pm 2{ }^{\circ} \mathrm{C}, 70 \% \mathrm{RH}\right)$ for about 10-12 days for larvae to achieve the late third instar, which was characterized by larval orientation and location on the diet. When the majority of larvae (about 80-90 \%) were moving horizontally on the diet, it indicated that they had reached the end of the third instar, had stopped feeding, and were crawling around to find suitable sites for pupation.

Late third instar larvae were separated by sieving the diet under water. The volume collected was recorded, and the larvae were placed on a thin layer of moist vermiculite (at 1:2 volume ratio of larvae:vermiculite) in plastic trays for pupation, which were kept in dark rooms $\left(24 \pm 2{ }^{\circ} \mathrm{C}, 65-75 \% \mathrm{RH}\right)$ for eight days. Pupae were then softly sieved and kept under the same conditions for at least 24 hours before placement in the adult holding cages.

\section{Quality control parameters}

Several parameters related to rearing and quality of $A$. fraterculus sp. 1 were assessed for each egg collection, such as eggs collected $(\mathrm{mL})$, eggs hatched, pupae collected $(\mathrm{mL})$, larval viability, pupal weight $(\mathrm{mg})$, eggpupae recovery, emergence, sex ratio, egg-adult period (days). For egg hatch, a sample of 100 eggs was collected after the bubbling period and placed on a black filter moist paper inside a Petri dish for incubation. After two days, the number of hatchings was counted, and the egg hatch rate was estimated based on (number of eggs hatched) (total eggs in the sample) $)^{-1}$.

\section{Data analysis}

A total of 54 insect generations were reared to maturity under laboratory conditions in the period between
November 2005 and August 2012, 53 of which were under entirely artificial conditions. Means and standard errors were estimated using the statistical package $\mathrm{R}$ version 2.15.1. The optimal agar concentration in larval diet was determined using generalized linear models (GLMs). Emergence and flight ability, egg-pupae recovery and larval viability data were submitted to logistic regression models adjusted for over-dispersion (Crawley, 2007). Afterwards, rank means were pair-wised compared by non-parametric t-test and $\alpha$ adjustment by Bonferroni's correction. The weight of the 100 pupae and egg-adult period data were analyzed by linear regression and means compared by Tukey test $(\alpha=0.01)$. All statistical analyses were run using the $\mathrm{R}$ program version 2.10.1.

\section{Results}

Among the agar concentrations assessed, the 0.34 $\%$ level resulted in better values over almost all the parameters evaluated (Table 1 ). The decrease from 1 to $0.34 \%$ of agar improved pupal weight by $5 \%\left(\mathrm{~F}_{(7,72)}=\right.$ $8.96 ; p<0.001)$, flight ability by $25 \%\left(\mathrm{~F}_{(7,72)}=18.09 ; p\right.$ $<0.001)$ and egg-pupae recovery by $31 \%\left(\mathrm{~F}_{(7,72)}=18.82\right.$, $p<0.001)$. Larval viability $(81 \%)$ and emergence $(81 \%)$ rates did not vary with agar concentrations in the diet $\left(\mathrm{F}_{(7,40)}=0.86, p=0.55\right.$ and $\mathrm{F}_{(7,72)}=1.66, p=0.13$ respectively). Egg-adult period was influenced by the agar concentration $\left(\mathrm{F}_{(7,72)}=3.89 ; p=0.0012\right)$; however, the values obtained at 1 and $0.34 \%$ agar did not differ (27 days).

The volume of eggs collected varied greatly over the 54 generations of $A$. fraterculus sp. 1 reared under artificial conditions (Figure 1) with an average of 102 $\pm 13.03 \mathrm{~mL}(\mathrm{n}=53)$ per generation and $5.03 \pm 0.10$ $\mathrm{mL}$ per day (Table 2). The volume of pupae produced reflected the volume of eggs inoculated, which varied according to the demand for insects. Maximum volumes were $591.15 \mathrm{~mL}$ of viable pupae per day and $18.10 \mathrm{~L}$ of eggs per generation, and means values were 296.52 $\pm 6.46 \mathrm{~mL}(\mathrm{n}=1,155)$ and $5.54 \pm 0.69 \mathrm{~L}(\mathrm{n}=53)$ respectively. Egg hatch rate increased in two intervals: the first between the $13^{\text {th }}$ and the $18^{\text {th }}$ generations and the second between the $25^{\text {th }}$ and the $30^{\text {th }}$ generations (Table 2). Values above $75 \%$ were achieved only after the $43^{\text {rd }}$ generation.

Larval viability had a drastic decrease between the $25^{\text {th }}$ and the $30^{\text {th }}$ generations but over the next six generations $\left(31^{\text {st }}\right.$ to $\left.36^{\text {th }}\right)$ a slight improvement in larval viability was detected, and from the $37^{\text {th }}$ generation onwards, larval viability again reached values close to the highest peak over the period. However, the average value of 0.29 was too low and must be increased. Pupal weight and emergence rate had averages of $14.26 \mathrm{mg} \mathrm{pupa}^{-1}$ and 85 $\%$ respectively (Table 2 ). Sex ratio averaged 0.53 female biased. Egg-pupae recovery was low, only 0.17 of the embryos reached the pupal stage. The egg-adult period lasted from 28 to 31 days, averaging 30 days. 
Table 1 - Quality parameters of Anastrepha sp.1 aff. fraterculus (mean \pm SE) when larvae were reared on artificial diets with concentrations of agar.

\begin{tabular}{ccccccc}
\hline Agar concentration & Pupal weight & Larval viability & Emergence & Flight ability & Egg-adult period & Egg-pupae recovery \\
\hline$\%$ & $\mathrm{mg}$ & rate $^{(1)}$ & rate & rate & days & rate \\
0.30 & $15.3 \pm 0.2 \mathrm{~b}$ & $0.77 \pm 0.04 \mathrm{a}$ & $0.79 \pm 0.02 \mathrm{a}$ & $0.52 \pm 0.03 \mathrm{de}$ & $27.6 \pm 0.16 \mathrm{a}$ & $0.14 \pm 0.02 \mathrm{f}$ \\
0.32 & $15.5 \pm 0.1 \mathrm{ab}$ & $0.80 \pm 0.03 \mathrm{a}$ & $0.79 \pm 0.02 \mathrm{a}$ & $0.64 \pm 0.01 \mathrm{bc}$ & $27.4 \pm 0.22 \mathrm{a}$ & $0.39 \pm 0.04 \mathrm{cde}$ \\
0.34 & $16.1 \pm 0.1 \mathrm{a}$ & $0.83 \pm 0.02 \mathrm{a}$ & $0.85 \pm 0.01 \mathrm{a}$ & $0.74 \pm 0.02 \mathrm{a}$ & $27.2 \pm 0.33 \mathrm{a}$ & $0.63 \pm 0.02 \mathrm{a}$ \\
0.36 & $16.1 \pm 0.1 \mathrm{a}$ & $0.82 \pm 0.05 \mathrm{a}$ & $0.82 \pm 0.02 \mathrm{a}$ & $0.69 \pm 0.02 \mathrm{ab}$ & $27.1 \pm 0.38 \mathrm{a}$ & $0.53 \pm 0.02 \mathrm{~b}$ \\
0.38 & $15.8 \pm 0.1 \mathrm{ab}$ & $0.84 \pm 0.03 \mathrm{a}$ & $0.80 \pm 0.02 \mathrm{a}$ & $0.58 \pm 0.02 \mathrm{~cd}$ & $27.5 \pm 0.17 \mathrm{a}$ & $0.28 \pm 0.05 \mathrm{ef}$ \\
0.40 & $15.2 \pm 0.2 \mathrm{~b}$ & $0.79 \pm 0.04 \mathrm{a}$ & $0.79 \pm 0.02 \mathrm{a}$ & $0.57 \pm 0.03 \mathrm{~cd}$ & $27.3 \pm 0.30 \mathrm{a}$ & $0.32 \pm 0.05 \mathrm{de}$ \\
0.70 & $14.7 \pm 0.2 \mathrm{~b}$ & $0.85 \pm 0.03 \mathrm{a}$ & $0.80 \pm 0.02 \mathrm{a}$ & $0.46 \pm 0.02 \mathrm{e}$ & $25.9 \pm 0.23 \mathrm{~b}$ & $0.43 \pm 0.03 \mathrm{bcd}$ \\
1.0 & $15.3 \pm 0.1 \mathrm{~b}$ & $0.81 \pm 0.01 \mathrm{a}$ & $0.84 \pm 0.01 \mathrm{a}$ & $0.55 \pm 0.02 \mathrm{de}$ & $27.3 \pm 0.30 \mathrm{a}$ & $0.48 \pm 0.04 \mathrm{bc}$ \\
\hline
\end{tabular}

Means followed by the same letter in columns do not differ $(p<0.01) ;(1) n=6$ replicates; the remaining parameters had $n=10$.

Table 2 - Rearing and quality control parameters (mean \pm SE) of Anastrepha sp.1 aff. fraterculus produced under artificial conditions.

\begin{tabular}{lccccccccc}
\hline Generations & $\begin{array}{c}\text { Daily volume of } \\
\text { eggs }\end{array}$ & Egg hatch & $\begin{array}{c}\text { Larval } \\
\text { viability }\end{array}$ & $\begin{array}{c}\text { Daily volume of } \\
\text { pupae }\end{array}$ & $\begin{array}{c}\text { Pupal } \\
\text { weight }\end{array}$ & Emergence & Sex ratio & $\begin{array}{c}\text { Egg-pupae } \\
\text { recovery }\end{array}$ & $\begin{array}{c}\text { Egg-adult } \\
\text { period }\end{array}$ \\
\hline $2^{\text {nd }}$ to $6^{\text {th(a) }}$ & $0.04 \pm 0.00$ & $0.28 \pm 0.01$ & $0.45 \pm 0.04$ & $10.04 \pm 2.72$ & - & $0.51 \pm 0.04$ & $0.48 \pm 0.02$ & $0.14 \pm 0.01$ & $28.45 \pm 0.54$ \\
$7^{\text {th }}$ to $12^{\text {th }}$ & $0.42 \pm 0.05$ & $0.15 \pm 0.01$ & $0.41 \pm 0.04$ & $62.19 \pm 7.95$ & - & $0.70 \pm 0.03$ & $0.48 \pm 0.02$ & $0.06 \pm 0.01$ & $29.23 \pm 0.40$ \\
$13^{\text {th }}$ to $18^{\text {th }}$ & $4.58 \pm 0.61$ & $0.35 \pm 0.02$ & $0.39 \pm 0.03$ & $216.22 \pm 39.95$ & - & $0.87 \pm 0.02$ & $0.51 \pm 0.01$ & $0.12 \pm 0.01$ & $28.65 \pm 0.34$ \\
$19^{\text {th }}$ to $24^{\text {th }}$ & $5.62 \pm 0.23$ & $0.49 \pm 0.01$ & $0.34 \pm 0.02$ & $291.71 \pm 16.36$ & $13.91 \pm 0.15$ & $0.85 \pm 0.01$ & $0.52 \pm 0.01$ & $0.15 \pm 0.01$ & $30.75 \pm 0.18$ \\
$2^{\text {th }}$ to $30^{\text {th }}$ & $5.61 \pm 0.22$ & $0.72 \pm 0.01$ & $0.15 \pm 0.01$ & $208.32 \pm 11.14$ & $14.63 \pm 0.12$ & $0.82 \pm 0.01$ & $0.55 \pm 0.00$ & $0.11 \pm 0.01$ & $30.65 \pm 0.15$ \\
$31^{\text {st }}$ to $36^{\text {th }}$ & $6.82 \pm 0.23$ & $0.73 \pm 0.00$ & $0.22 \pm 0.01$ & $397.11 \pm 11.37$ & $14.42 \pm 0.09$ & $0.90 \pm 0.00$ & $0.52 \pm 0.00$ & $0.16 \pm 0.00$ & $30.52 \pm 0.08$ \\
$37^{\text {th }}$ to $42^{\text {nd }}$ & $3.84 \pm 0.12$ & $0.72 \pm 0.01$ & $0.38 \pm 0.01$ & $405.68 \pm 14.18$ & $13.53 \pm 0.05$ & $0.86 \pm 0.00$ & $0.54 \pm 0.00$ & $0.30 \pm 0.01$ & $28.43 \pm 0.22$ \\
$43^{\text {rd }}$ to $48^{\text {th }}$ & $4.04 \pm 0.15$ & $0.76 \pm 0.01$ & $0.35 \pm 0.01$ & $377.26 \pm 12.87$ & $14.49 \pm 0.06$ & $0.87 \pm 0.01$ & $0.56 \pm 0.00$ & $0.27 \pm 0.01$ & $29.66 \pm 0.16$ \\
$49^{\text {th }}$ to $54^{\text {th }}$ & $5.43 \pm 0.20$ & $0.80 \pm 0.01$ & $0.29 \pm 0.01$ & $454.60 \pm 26.24$ & $14.30 \pm 0.08$ & $0.89 \pm 0.01$ & $0.55 \pm 0.01$ & $0.23 \pm 0.01$ & $30.61 \pm 0.17$ \\
\hline Mean $^{(b)}$ & $5.03 \pm 0.1$ & $0.64 \pm 0.01$ & $0.29 \pm 0.01$ & $317.55 \pm 6.48$ & $14.26 \pm 0.04$ & $0.85 \pm 0.003$ & $0.53 \pm 0.0020 .17 \pm 0.003$ & $30.04 \pm 0.07$ \\
\hline
\end{tabular}

-Data not available; (a)Domestication period (criteria used to group the generations in intervals); (b) Excludes domestication period, $\mathrm{N}=1076$ egg collections.

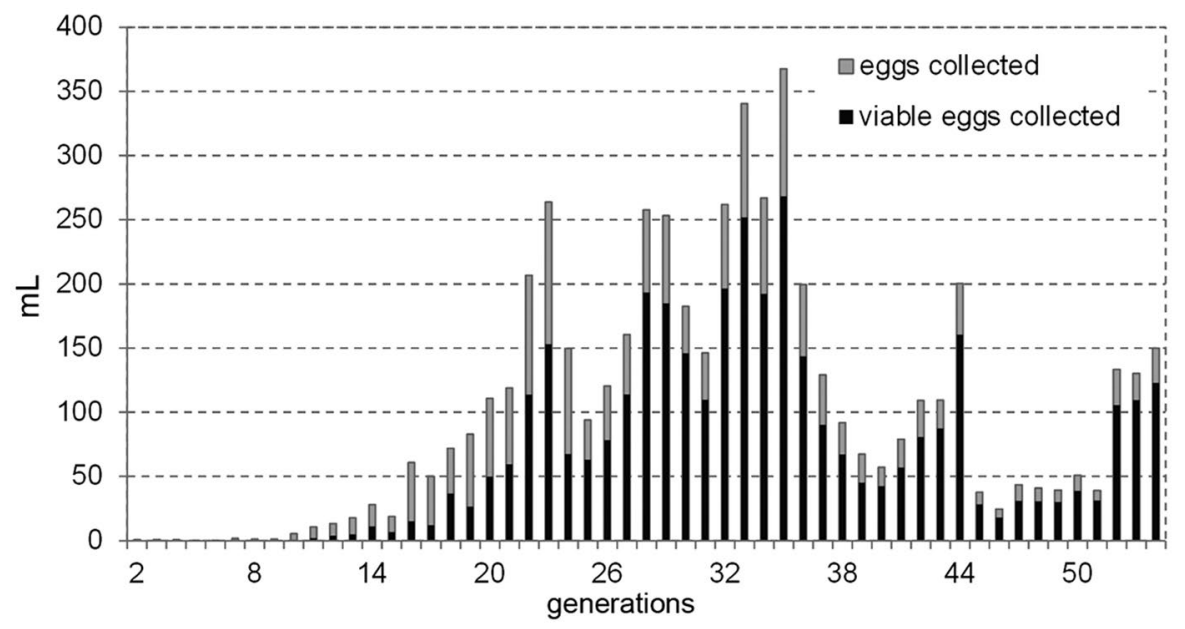

Figure 1 - Total volume of eggs per generation of Anastrepha sp.1 aff. fraterculus collected under artificial conditions.

\section{Discussion}

The volume of insects produced is an important parameter in this study, since it provides a measurement of the $A$. fraterculus sp. 1 production in the present facilities.
However, it is important to consider both production and the quality parameters for the insects. Egg hatch, egg-pupae recovery, larval viability, pupal weight, emergence, and sex ratio reflect the quality of the insects produced and production efficiency at different stages of insect development. 
Egg hatch is a parameter that requires improvement. The addition of raw wheat germ (Triticum aestivum L.) in adult diet and the change in the protein source from imported to local hydrolyzed yeast (Morelli et al., 2012), as well as the bubbling of eggs before seeding, increased egg hatch in the present methodology that can be improved further by more effectively preventing egg desiccation. Vera et al. (2007) reported egg hatch rates above $80 \%$ when the relative humidity in the room containing adult cages was controlled with a humidifier. Alternatives that retain moisture on the oviposition panel are also promising, such as Fuceleron ${ }^{\mathrm{TM}}$ gel which has been used for Anastrepha spp. mass-rearing in Mexico (Flores et al., 2012).

The drastic decrease in larval viability between the $25^{\text {th }}$ and $30^{\text {th }}$ generations was due to a batch of wheat germ that killed the larvae, which was replaced once the problem was detected. The use of dietary ingredients from different batches or product suppliers may interfere in larval performance as, for example, in the case of contamination with pesticide residue, which likely occurred. Nevertheless, larval viability rate was also very low, and improvements should be made in diet consistency as well as in handling.

Vera et al. (2007) achieved a value of $67 \%$, and the main difference between that study and the current one was in the method used to collect larvae. Vera et al. (2007) placed the diet trays on sterilized sand, and once larvae had completed the third instar, they stopped feeding and moved out of the trays by themselves. Thus, multiple larval harvestings from a single diet tray were done on different days. In this study, larvae were removed by washing the diet on a sieve when most larvae had stopped feeding, thus harvesting larvae only once per tray. Since not all larvae had reached late third instar at the time of harvesting (10-20\%), the amount of pupae recovered was lower than with multiple harvestings (Vera et al., 2007), which directly affected larval viability and egg-pupae recovery.

Pupal weight and emergence were considered satisfactory according to standard protocols (FAO, 2003) and above the values obtained by Vera et al. (2007). FAO (2003) does not specify standards for $A$. fraterculus, however, both values are very close to those recommended for $A$. obliqua and $A$. suspensa. The sex ratio also met FAO (2003) standards. So, despite the low larval viability, both the parameters of pupal weight and high adult emergence demonstrate that the diet is nutritionally adequate, because it produces high-quality larvae and pupae, but the physical structure of the diet and handling of larvae can be improved. The current method for collecting the larvae favored the homogenization of insect development in the rearing and seemed to select more vigorous insects, once the pupae quality was higher.

Egg-pupae recovery was low, even though flies had been selected for artificial diet over several generations. Values above 0.4 can be achieved (Jaldo et al.,
2001; Vera et al., 2007). The process of larval collection resulted in recovery rates of second and early thirdinstar larvae around 10-20\%, discarding deformed puparium, and therefore, low pupae recovery. Vera et al. (2007) used a different system for larval collection and achieved values greater than $50 \%$. Despite the lower yield compared to the system of Vera et al. (2007), our system provides higher-quality insects. Collecting eggs at shorter intervals as suggested here would be an easy alternative to implement for improving the current system of larval collection because it would homogenize larval development and thus increase egg-pupae recovery. Eight-hour intervals between egg collections would be logistically feasible as they coincide with the employees' shifts at fruit fly biofactories, which operate $24 \mathrm{~h}$.

This system of artificial rearing for $A$. fraterculus sp.1, developed in Brazil, allows for the production of a large amount of insects of excellent quality using local ingredients and little agar in the diet composition. By reducing the interval of egg collection, the system might be optimized in terms of insect yield and, therefore, supply the demands of $A$. fraterculus sp. 1 for IPM purposes. However, studies that address sterilization dosage and mating competitiveness of the sterile males, as well as mating compatibility between the reared strain and target populations, are recommended to improve further SIT.

\section{Acknowledgements}

To Maria Fernanda Peñaflor and Neivaldo Costa for valuable reviews, Biofábrica Moscamed Brasil for providing three student fellowships and the International Atomic Energy Agency for partial funding through Research Contract RC13017.

\section{References}

Allinghi, A.; Calcagno, G.; Petit-Marty, N.; Gomez-Cendra, P.; Segura, D.; Vera, M.T.; Cladera, J.; Gramajo, C.; Willink, E.; Vilardi, J.C. 2007. Compatibility and competitiveness of a laboratory strain of Anastrepha fraterculus (Diptera: Tephritidae) after irradiation treatment. Florida Entomologist 90: 27-32.

Araújo, E.L.; Zucchi, R.A. 2006. Spine measurements in the characterization of five species of the Anastrepha fraterculus group (Diptera: Tephritidae). Neotropical Entomology 35: 329337 (in Portuguese, with abstract in English).

Crawley, M.J. 2007. The R Book. John Wiley, Chichester, UK.

Food and Agriculture Organization [FAO]. 2003. Manual for product quality control and shipping procedures for sterile mass-reared tephritid fruit flies. FAO/IAEA. Available at: http://www-naweb.iaea.org/nafa/ipc/public/ipc-mass-rearedtephritid.html Accessed Feb 17, 2013.

Flores, H.S.; Hernández, E.; Toledo, J. 2012. Development of an artificial rearing system for Anastrepha fraterculus (Diptera: Tephritidae). Acta Zoologica Mexicana 28: 321-340 (in Spanish, with abstract in English). 
Gomez-Cendra, P.; Segura, D.; Allinghi, A.; Cladera, J.; Vilardi, J. 2007. Comparison of longevity between a laboratory strain and a natural population of Anastrepha fraterculus under field cage conditions. Florida Entomologist 90: 147-153.

Jaldo, H.E.; Gramajo, M.C.; Willink, E. 2001. Mass-rearing of Anastrepha fraterculus (Diptera: Tephritidae): a preliminary strategy. Florida Entomologist 84: 716-718.

Knipling, E.F. 1955. Possibilities of insect control or eradication through the use of sexually sterile males. Journal of Economic Entomology 48: 459-462.

Knipling, E.F. 1992. Principles of Insect parasitism analyzed from new perspectives: Practical implications for regulating insect populations by biological means. US Department of Agriculture, Washington DC, USA. (Agriculture Handbook, 639).

Malavasi, A.; Zucchi, R.A.; Sugayama, R. 2000. Biogeografia = Biogeography. p. 93-98. In: Malavasi, A.; Zuchhi, R.A., eds. Moscas-das-frutas de importância econômica no Brasil: conhecimento básico e aplicado = Fruit flies of economic importance in Brazil: basic and applied knowlegdment. Holos, Ribeirão Preto, SP, Brazil (in Portuguese).

Montoya, P.; Liedo, P.; Benrey, B.; Cancino, J.; Barrera, J.F.; Sivinski, J.; Aluja, M. 2000. Biological control of Anastrepha spp. (Diptera: Tephritidae) in mango orchards through augmentative releases of Diachasmimorpha longicaudata (Ashmed) (Hymenoptera: Braconidae). Biological Control 18: 216-224.

Morelli, R.; Costa, K.Z.; Faggioni, K.M.; Costa, M.L.Z.; Nascimento, A.S.; Pimentel, R.M.A.; Walder, J.M.M. 2012. New protein sources in adult diet for mass-rearing of Anastrepha fraterculus (Diptera: Tephritidae). Brazilian Archives of Biology and Technology 55: 827-833.

Ovruski, S.M.; Bezdjian, L.P.; van Nieuwenhove, G.A.; Albornoz-Medina, P.; Schliserman, P. 2011. Host preference by Diachasmimorpha longicaudata (Hymenoptera: Braconidae) reared on larvae of Anastrepha fraterculus and Ceratitis capitata (Diptera: Tephritidae). Florida Entomologist 94: 195-200.
Salles, L.A.B. 1992. Rearing technique for Anastrepha fraterculus (Wiedemann, 1830) (Diptera: Tephritidae) in laboratory. Anais da Sociedade Entomológica do Brasil 21: 479-486 (in Portuguese, with abstract in English).

Selivon, D.; Perondini, A.L.P.; Morgante, J. 2005. A geneticmorphological characterization of two cryptic species of Anastrepha fraterculus complex (Diptera: Tephritidae). Annals of the Entomological Society of America 98: 367-381.

Seo, S.T.; Tang, C.S. 1982. Hawaiian fruit flies (Diptera: Tephritidae): toxicity of benzyl isothiocyanate against eggs or 1st instars of three species. Journal of Economic Entomology 75: 1132-1135.

Silva-Neto, A.M.; Santos, T.R.O.; Dias, V.S.; Joachim-Bravo, I.S.; Benevides, L.J.; Benevides, C.M.J.; Silva, M.V.L.; Santos, D.C.C.; Oliveira, G.B.; Walder, J.M.M.; Paranhos, B.A.J.; Nascimento, A.S. 2012. Mass-rearing of Mediterranean fruit fly using low-cost yeast products produced in Brazil. Scientia Agricola 69: 364-369.

Sivinski, J.M.; Calkins, C.O.; Baranowski, R.; Harris, D.; Brambila, J.; Diaz, J.; Burns, R.E.; Holler, T.; Dodson, G. 1996. Suppression of Caribbean fruit fly (Anastrepha suspensa (Loew) Diptera: Tephritidae) population through releases of the parasitoid Diachasmimorpha longicaudata (Ashmead) (Hymenoptera: Braconidae). Biological Control 6: 177-185.

United States Department of Agriculture [USDA]. 2010. United States And Mexico Lower Rio Grande Valley Mexican Fruit Fly Eradication Program Review: Final Report. USDA/APHIS, Washington, DC, USA.

Vera, T.; Abraham, S.; Oviedo, A.; Willink, E. 2007. Demographic and quality parameters of Anastrepha fraterculus (Diptera: Tephritidae) maintained under artificial rearing. Florida Entomologist 90: 53-5 